\title{
INFLUENCIAS HISPANAS EN LA ARQUITECTURA DE LA HABANA ENTRE LOS SIGLOS XIX Y XX
}

\author{
HISPANIC INFLUENCE IN THE ARCHITECTURE OF \\ HAVANA BETWEEN THE NINETEENTH AND TWENTIETH
}

\author{
RAFAEL LóPEZ GuZMÁN \\ Universidad de Granada, España \\ rlopez@ugr.es
}

La independencia de Cuba a fines del siglo XIX no supuso el fin de las relaciones ni de las influencias de España en la isla. Por un lado, las asociaciones de carácter cultural relacionadas con las regiones de origen en la Península Ibérica se visualizaron con grandes arquitecturas y, por otro, las influencias formales relacionadas con el orientalismo y la Alhambra también son visibles en la arquitectura de La Habana.

Palabras clave: Neoárabe, Centros culturales, Arquitectura Habana, Influencias Hispanas, Cerámica sevillana.

Cuban independence, taking place at the end of the XIXth Century, did not imply the end of the influence of, and the relationship with Spain. On the one hand, cultural associations related to different Iberian regions made themselves present in Cuban urban landscapes through remarkable architecture; on the other, formal influences related to Orientalism and Alhambra were present in Havana architecture.

Keywords: Cultural centers; Havana Architecture; Hispanic Influence; Neo-Islamic Style; Sevillian Pottery.

El crecimiento de la ciudad de la Habana en el siglo XIX supondrá la entrada en la misma de modas constructivas ajenas a las tendencias mantenidas durante el periodo virreinal. Al igual que en el resto de los espacios culturales de occidente, los denominados "neos" o historicismos hacen su presencia apoyados, en el caso cubano, e inicialmente, en las tendencias que se desarrollan en la Península Ibérica al integrarse todavía la isla en el organigrama político hispano. Cronológicamente este proceso se enmarca en la búsqueda de estilos "nacionales", que en nuestro caso, el mudéjar o el gótico marcarán acciones concretas de carácter 
institucional pero, más adelante, en los límites del ochocientos, aparecen vigentes propuestas generalizadas en toda Europa en relación con los viajeros románticos y la admiración por las culturas orientales, siendo enormemente significativas las aportaciones derivadas del mundo islámico. En este sentido, habrá que considerar el nacimiento del regionalismo que trata de recuperar lo autóctono y que en el caso español aúna influencias andalusíes con otros estilos históricos, conformando obras donde lo decorativo domina sobre lo arquitectónico y donde cerámicas, yeserías y vaciados en cemento proliferan.

Estas nuevas arquitecturas se desarrollan en La Habana básicamente en el primer tercio del siglo XX, pero tienen sus precedentes en el XIX, momento que, a nivel histórico, coincide con la crisis de la presencia hispana en Cuba.

El 1 de enero de 1899 comenzaba el siglo XX para Cuba, fecha en que se entregaba el mando de la isla por parte española al nuevo ocupante, los Estados Unidos de Norteamérica. A nivel cultural se traducía la situación en un rechazo a todo lo hispánico y, en paralelo, a la búsqueda de una nueva imagen nacional, lo que llevó a indagar en modelos estéticos europeos y relacionados con el "buen vecino" del norte.

No obstante, las ansias de transformación no hubieran sido suficientes para la definición de la imagen de La Habana sin la existencia de profesionales capaces de lograr un diálogo coherente entre las influencias foráneas y los condicionantes locales. Al comienzo del nuevo siglo, Cuba no solo contaba con los graduados de la Escuela Profesional de Maestros de Obras, Agrimensores y Aparejadores, fundada en 1863, sino también con los arquitectos cubanos egresados de universidades extranjeras. A esto se sumó el establecimiento en el país de compañías constructoras norteamericanas con una vasta experiencia, que fueron las responsables de la introducción y desarrollo de nuevos materiales y tecnologías. No menos importante fue la presencia de operarios experimentados en espera de trabajo, luego del paro constructivo ocasionado por la Guerra de la Independencia (1895-1898), y la propagación de talleres de fundición seriada de piezas decorativas que permitían la selección rápida de combinaciones de elementos de acuerdo con el gusto del momento y las posibilidades económicas del propietario ${ }^{1}$.

A estas condiciones hay que añadir el fuerte flujo emigratorio hacia Cuba en las últimas décadas del siglo XIX y primeras del XX. Hacia 1880 muchos norteamericanos se establecieron en la isla, lo cual se intensificó notablemente con el recién iniciado siglo y el nuevo gobierno que estimuló la inmigración. Así mismo se incrementó la llegada de emigrantes, mayormente españoles, además de otros provenientes de diversos países, que junto con los cubanos exiliados que regresaban a su país, influenciaron significativamente en la conformación de las ciudades. Además de las necesidades que crearon con su presencia y su

${ }^{1}$ RODRÍGUEZ, Eduardo Luis: La Habana: arquitectura del siglo XX. Barcelona, 1998 , p. 47. 
actividad, lo más distintivo fue la influencia que traían consigo y que ellos mismos representaban.

En cuanto a la emigración española, en 1898, debido al término del período hispánico, se detuvo temporalmente la llegada a Cuba de personas provenientes de la Península e, incluso, un buen número decidió regresar. No obstante, se trató de una reacción temporal. Con el comienzo del siglo el flujo migratorio tomó impulso y con mayor intensidad, debido a las nuevas condiciones políticas cubanas. De hecho, un décimo de la población de la isla, durante las tres primeras décadas del siglo XX, era de origen español. Estos emigrantes tuvieron dos ocupaciones básicas en la isla. Por un lado, trabajos agrícolas en relación con la caña de azúcar y, en segundo lugar, trabajos en la ciudad, donde fue bastante generalizado el integrarse o crear pequeñas y grandes fábricas y talleres de producción de diferentes elementos constructivos y decorativos como, por ejemplo, mosaicos, tejas, losas de techo, azulejos o producción de cemento, entre otros. Por esta razón, la inmigración española en Cuba estuvo vinculada de forma activa al afán constructivo y aportó múltiples influencias que contribuyeron a la conformación de la ciudad en las primeras décadas del siglo XX.

Por otro lado, hay que señalar que frente a ese rechazo comentado sobre lo hispánico, las comunidades de españoles allí residentes trataron de demostrar: “...que aún eran portadoras de una fuerza renovadora, comienzan a levantar suntuosos edificios para albergar sus sedes sociales, palacios que son hoy paradigmas dentro de la arquitectura habanera, entre los que se encuentran el Centro Gallego, el Centro Asturiano, la Sociedad de Dependientes del Comercio y el Casino Español..."2. Este asociacionismo se cimentó, primero en la Constitución Española ${ }^{3}$ del momento y, más tarde, en la aprobación de la Ley de Asociaciones refrendada el 30 de junio de 1888, aunque con normativas parciales previas que arrancaban desde una decena de años antes $^{4}$. Con la promulgación de la Ley de Asociaciones y Reuniones Públicas que facilitaba los trámites legales para la creación de sociedades, el fenómeno asociativo se intensifica, se diversifica y se extiende por todo el país ${ }^{5}$. Sobre esa infraestructura legal, en la Habana se crean la Sociedad de Beneficencia de Naturales de Galicia (1871), la Sociedad Vasco-Navarra de Beneficencia (1877), la Sociedad Asturiana de Beneficencia (1877), el Centro Gallego (1871), la Sociedad de Beneficencia

${ }^{2}$ GÓMEZ DÍAZ, Francisco: De Forestier a Sert. Ciudad y arquitectura en La Habana (1925-1960). Madrid, 2008, p. 60.

${ }^{3}$ En el artículo 13 de la Constitución de la Restauración de 1876 se reconocía que todo español tenía derecho a asociarse para los fines de la vida humana, por esa razón surgieron, desde el año 1878, múltiples sociedades y corporaciones.

${ }^{4}$ Sobre este tema, Cfr. FLAQUER MONTEQUI, Rafael: "Los derechos de asociación, reunión y manifestación”, Ayer, 34, 1999, pp. 155-175.

${ }^{5}$ BARCÍA, María del Carmen: "De la reestructuración a la crisis: La sociedad cubana a finales del siglo XIX”, Historia Contemporánea, 19, 1999, pp. 129-153. 
de Naturales de Andalucía (1881), la Sociedad Montañesa de Beneficencia (1882), la Sociedad Castellana de Beneficencia (1885), el Centro Catalán (1885), el Centro Canario (1885), el Centro Asturiano (1886), la Sociedad Burgalesa de Beneficencia (1893), la Sociedad Murciano-Valenciana de Beneficencia (1902), el Centro Balear (1895), la Asociación Canaria (1907), el Centro Vasco (1908), el Centro Aragonés (1908), el Centro Castellano (1909), el Gran Foment Catalá (1909), el Centro Montañés (1911), la Sociedad Canaria de Beneficencia (1917) y la Sociedad Aragonesa de Beneficencia $(1923)^{6}$. Estos centros comenzarían a monumentalizarse visualmente a partir de 1907 con la construcción del Palacio de los Dependientes del Comercio diseño de Arturo Amigó.

Y aunque estamos hablando de edificios de inicios del siglo XX como el Centro Gallego, diseñado por el belga Paul Belau e inaugurado en 1914 ${ }^{7}$, hemos de señalar que su fundación como institución es ochocentista (31 de diciembre de $1871)^{8}$, comenzando una serie de actividades de carácter social y de beneficencia pública, tanto en el interior como en el exterior de la isla, que podemos concretar, entre otras, en la fundación de la clínica La Benéfica ${ }^{9}$, la Caja de Ahorros y Banco Gallego, una Academia de Bellas Artes y una Escuela de Música con el rango de Conservatorio $^{10}$. La fuerza de esta institución puede verse a través de sus asociados que en 1920 ascendían a 64.000. Hoy día este edificio es el Gran Teatro ${ }^{11}$ situado en el Parque Central, coronando, junto al Capitolio, el Paseo del Prado.

Por su parte, el Centro Asturiano ${ }^{12}$ arranca sus actividades en el siglo XIX pero no es hasta 1923 el año en que comienza la construcción de su monumental

${ }^{6} \mathrm{~A}$ estas sociedades de carácter regional se añaden otras de carácter local como la Alianza Aresana (1904) en relación con los oriundos de Ares (La Coruña). En 1927 se contabilizaban en La Habana hasta 135, a las que había que añadir otras instituciones con fines similares como orfeones, grupos teatrales, casinos, cámaras de comercio, asociaciones deportivas, etc.

${ }^{7}$ Se construyó sobre el teatro Tacón que quedó integrado en la nueva construcción. La imagen final es la de un edificio ecléctico con formas neobarrocas de ascendencia francesa. Cfr. MARTIIN ZEQUEIRA, María Elena y RODRÍGUEZ FERNÁNDEZ, Eduardo Luis: La Habana. Guía de Arquitectura. Sevilla, 1998, p. 145. Véase, también: RODRÍGUEZ, Eduardo Luis: La Habana. Arquitectura del siglo XX..., op. cit., p. 162.

${ }^{8}$ El primer edificio estuvo situado en el Paseo del Prado $n^{\circ}$ 60. Actualmente es sede de una escuela de primaria con el nombre de "Concepción Arenal".

${ }^{9}$ Hospital fundado en 1894, que durante bastante tiempo solo atendía a hombres.

${ }^{10} \mathrm{Su}$ importancia hizo que, incluso, tuviera sucursales como la de Regla, actual Casa de la Cultura "Roberto Faz Monzón".

${ }^{11}$ Actualmente es un gran complejo cultural integrado por varias compañías artísticas, entre ellas el Ballet Español de La Habana; alojando también la Federación de Sociedades Españolas y la Sociedad de Beneficencia Naturales de Galicia.

${ }^{12}$ Dependiente del Centro Asturiano se fundó en 1896 la clínica la "Covadonga" (Calzada del Cerro, 1551), en honor a la patrona de Asturias. 
edificio convertido en la actualidad en Museo Nacional de Bellas Artes de Cuba ${ }^{13}$. $\mathrm{Su}$ arquitecto Manuel del Busto y Delgado (1874-1948), aunque oriundo de San Rosendo (Cuba) desarrolló la mayor parte de su obra en Asturias siendo excepcional en su producción el Centro Asturiano de La Habana ${ }^{14}$.

Si las anteriores son las más significativas por la monumentalidad de sus edificaciones, la primera de las asociaciones de carácter regional fundada en Cuba fue la Sociedad de Beneficencia Naturales de Cataluña en 1841, aunque la ubicación en el edificio actual es de mediados del siglo $\mathrm{XX}^{15}$ situado en la calle Consulado $\mathrm{n}^{\circ} 68$, entre Refugio y Genios.

Algo similar sucede con el Casino Español. El club se fundó en 1869 pasando por varias sedes hasta que en 1912 se comenzó la construcción, bajo la dirección del arquitecto Louis Dediot, del que sería el edificio definitivo ${ }^{16}$. Situado en el Paseo del Prado responde a un proyecto ecléctico donde se mezclan elementos de carácter barroco en la composición con formas decorativas de grutescos y candelieri que le inscriben dentro de la corriente neorrenacentista. La espacialidad y monumentalidad interior, así como el ornato de sus salones, hizo que tras la revolución se cambiara su uso, convirtiéndose en Palacio de los Matrimonios.

Otro edificio significativo será la Sociedad de Dependientes del Comercio de La Habana fundada en $1880^{17}$. Aunque iniciaron su andadura en un edificio alquilado al Ateneo de La Habana, en 1907 construyeron una nueva sede, obra de Arturo Amigó, que actualmente funciona como Escuela Nacional de Ballet,

${ }^{13}$ El 9 de noviembre de 1923 se colocó la primera piedra de este edificio, procedente de las canteras de Covadonga, en Asturias. Tenía tallado el escudo de Asturias y la inscripción: "Del Cabildo de Covadonga al Centro Asturiano de La Habana". Sus salones alcanzaron una notable fama por los bailes que organizaba la asociación.

${ }^{14} \mathrm{El}$ edificio recuerda lejanamente el Palacio de Comunicaciones de Madrid, presentando características neorrenacentistas en el tratamiento de las fachadas. Cfr. MARTÍN ZEQUEIRA, María Elena y RODRÍGUEZ FERNÁNDEZ, Eduardo Luis: La Habana. Guía de Arquitectura..., op. cit., p.146. Véase, también: RODRÍGUEZ, Eduardo Luis: La Habana. Arquitectura del siglo XX..., op. cit., pp. 162-164.

${ }^{15} \mathrm{La}$ institución se disolvió en 1965 , siendo depositaria de su biblioteca y documentación el Archivo Pompeu Fabra que funciona en La Habana con la colaboración de la Generalitat de Catalunya desde 1992.

${ }^{16}$ Cfr. MARTÍN ZEQUEIRA, María Elena y RODRÍGUEZ FERNÁNDEZ, Eduardo Luis: La Habana. Guía de Arquitectura..., op. cit., p.156.

${ }^{17}$ Este centro ofreció una amplia labor de formación de los asociados, así como asistencia sanitaria en la casa de salud La Purísima Concepción que contaba con un cuerpo de facultativos capacitados. Incluso, el Centro, tuvo sus órganos de prensa como "El Progreso Mercantil”, primero, y "El Progreso Comercial e Industrial”, después. Cfr. BARCÍA, María del Carmen: De la reestructuración a la crisis...,op. cit., pp. 147-148. 
también en el Paseo de Prado. Formalmente nos remite a esquemas neorrenacentistas de ascendencia veneciana ${ }^{18}$.

Estos centros hispanos de carácter asociacionista tuvieron su época de esplendor coincidiendo con el periodo de mayor flujo migratorio, desde la segunda década del siglo XX hasta los años 50, cuando las sociedades de emigrantes integraban a una tercera parte de la comunidad española y llegaron a contar con más de 400.000 asociados $^{19}$.

Pero también la influencia hispánica apareció en espacios específicos de carácter comercial o industrial. Un ejemplo de ello sería la Real Fábrica de Tabacos Partagás fundada por el empresario catalán Jaime Partagás en 1827. De una pequeña industria artesanal pasaría a ser uno de los emblemas de la manufactura tabaquera cubana registrada desde 1845 . El edificio, de inicios del siglo $\mathrm{XX}^{20}$, situado en la calle Industria, sigue en uso y responde a un proyecto de fachada de carácter historicista organizado en cuatro alturas con vanos bien distribuidos y pilastras clásicas que marcan las alturas y el ritmo compositivo. El frontón de formas cóncavo-convexas recupera movimientos barrocos y sirve como espacio público de la marca.

También la Farmacia La Reunión, fundada en La Habana el 20 de Mayo de 1853 por la sociedad Catalá, Sarrá y Co. en la calle Teniente Rey n 41 , esquina Compostela, fue extendiéndose por los locales colindantes y ganando en espacialidad y ornato, llegando a considerarse a principios del siglo XX la segunda en importancia en el mundo y la primera en $\mathrm{Cuba}^{21}$.

No podemos olvidar, tampoco, la presencia de españoles en construcciones de carácter lúdico como el Teatro Irioja ${ }^{22}$ (Teatro Martí a partir de 1900), fundado por el empresario de origen vasco Ramón Irioja en 1884 con planteamientos arquitectónicos neoclásicos diseñados por el arquitecto Alberto de Castro. E, igualmente, el Cine-Teatro Payret en el Paseo del Prado, esquina San José,

${ }^{18}$ Cfr. MARTÍN ZEQUEIRA, María Elena y RODRÍGUEZ FERNÁNDEZ, Eduardo Luis: La Habana. Guía de Arquitectura..., op. cit., p. 158. Véase, también: RODRÍGUEZ, Eduardo Luis: La Habana. Arquitectura del siglo XX..., op. cit., p. 160.

${ }^{19}$ Muchas de estas asociaciones sobrevivieron al triunfo de la revolución de 1959, pero la asunción por parte del estado cubano de la asistencia sanitaria y la educación redujo sus funciones a actividades recreativas y culturales. En algunos casos, se produjo también la nacionalización de la sede social y, con ello, la disolución de las entidades.

${ }^{20}$ MARTÍN ZEQUEIRA, María Elena y RODRÍGUEZ FERNÁNDEZ, Eduardo Luis: La Habana. Guía de Arquitectura..., op. cit., p. 171.

${ }^{21}$ En la actualidad, y tras la consiguiente restauración, se ha convertido en el Museo de la Farmacia Habanera.

${ }^{22}$ Cfr. MARTÍN ZEQUEIRA, María Elena y RODRÍGUEZ FERNÁNDEZ, Eduardo Luis: La Habana Colonial (1519-1898). Sevilla, 1995, p. 114; y, MARTÍN ZEQUEIRA, María Elena y RODRÍGUEZ FERNÁNDEZ, Eduardo Luis: La Habana. Guía de Arquitectura..., op. cit., p. 138. 
inaugurado en 1877 por el catalán Joaquín Payret y por Fidel Luna, arquitecto de la misma procedencia. El edificio original sería demolido en la década de los cincuenta del siglo XX y reconstruido bajo parámetros clasicistas.

También existen algunos ejemplos de carácter deportivo como el frontón JaiAlai inaugurado en 1901. La rápida afición que generó en la isla supuso que se crearan frontones en otras ciudades y que en 1922 se constituyera el frontón Habana-Madrid para uso exclusivo femenino. Quizás por esta razón se le denominaba popularmente como La Bombonera.

A nivel estético, "...el panorama arquitectónico cubano de principios del siglo XX muestra una diversidad que había estado ausente en épocas anteriores. A la lógica persistencia del sobrio neoclasicismo decimonónico se sumó, en avalancha expresiva sin precedentes, cuanta imagen exótica fuera imaginable por proyectistas y promotores de obras, como si con la libertad política hubiese llegado también la libertad de escoger entre un repertorio de nuevas opciones artísticas y se aceptaran todas a la vez"23. Dicha arquitectura ha sido definida como ecléctica debido a las diversas influencias extranjeras presentes en los elementos decorativos y sus combinaciones, lo cual distingue las edificaciones de este período ${ }^{24}$.

El eclecticismo era la arquitectura más adaptable a las condiciones de entonces, puesto que se basaba en la libre elección, estando permitido mezclar de forma aleatoria elementos académicos y rasgos vernáculos. Dicha arquitectura abogaba por el carácter simbólico de la decoración y no permitía que solo las clases pudientes pudieran acceder a ella, por lo que los menos ricos y los "nuevos ricos" podían optar, mediante reproducciones, por una arquitectura cuya esencia se centraba en el ornato superficial.

Los primeros ejemplos cubanos de arquitectura ecléctica prácticamente nacieron con el siglo. En el Paseo del Prado fue donde primero se puso de manifiesto el catálogo de posibilidades, difundiéndose, a continuación, por las zonas de expansión urbana. La burguesía cubana se identificó con una ciudad de expresiones simbólicas, en la cual podía relacionarse con facilidad el lugar de los edificios y sus funciones con opciones estilísticas específicas.

El auge constructivo, ya comentado, de inicios del siglo XX acarreó el surgimiento de talleres de producción de elementos ornamentales prefabricados. Estos talleres brindaban una gran variedad de motivos y hasta daban la posibilidad de

${ }^{23}$ RODRÍGUEZ, Eduardo Luis: La Habana: arquitectura del siglo XX..., op.cit., p. 45.

${ }^{24}$ Sobre el eclecticismo habanero son fundamentales los trabajos de: ZARDOYA LOUREDA, María Victoria: Estudio tipológico de las viviendas eclécticas en las Calzadas de La Habana. La Habana, 1998; "Algo más del estilo sin estilo", Arquitectura y Urbanismo, Vol. XXII, 4, 2001, pp. 36-45; "Ornamento por encargo", Opus Habana, 3, 2001, pp. 44-52 ; "De lo que nos trajeron en el XX", Arquitectura y Urbanismo, 2-3, 2008, pp. 36$41 ; \mathrm{y}$, "De cuando el ornamento no era delito. Apuntes sobre el eclecticismo cubano", Arquitectura Cuba, 377, 1998, pp. 38-44. 
pedirlos por encargo. La utilización del cemento como base para la elaboración de estos elementos permitió que su realización fuese sencilla y rápida, por lo que se lograba una mayor productividad. En las revistas de la época se encontraban anuncios que posibilitaban que los propietarios pudieran escoger entre un estilo u otro, e incluso, que ellos mismos combinaran la decoración que conformaría sus fachadas. Esta gran variedad permitió que aunque el tipo de casa fuera el mismo no hubiera una igual a la otra debido a la particularidad que adoptaban con solo el cambio de la ubicación, diseño y cantidad de elementos ornamentales que componían sus fachadas. "La existencia de estos talleres coadyuvó a lograr la gran unidad, a pesar de la diversidad, que caracterizó a la arquitectura de estos años. Gracias a ellos se pudo construir respetando las exigencias de "decoro urbano" que establecían las Ordenanzas de Construcción, sin que mediara en la mayoría de los casos la presencia de un profesional”25.

Dentro de la gama estética que brindaban estos catálogos de fábricas el neoárabe tuvo una presencia significativa con variedades estructurales en fachadas e interiores que le convierten, por su número y cualidad, en uno de los más representativos del ámbito hispanoamericano ${ }^{26}$. Los ejemplos identificados se encuentran esparcidos por toda la ciudad, aunque sí es un factor común lo próximos que están a vías de comunicación importantes. No se puede identificar un autor único, ya sea arquitecto, maestro de obras, ingeniero o propietario determinado, que genere la compleja serie de realizaciones. Si podemos afirmar, en cuanto al ámbito temporal, que tuvo su auge en las dos primeras décadas del siglo XX.

Uno de los elementos presentes en buena parte de estas arquitecturas es el azulejo sevillano procedente, principalmente, de las fábricas de Mensaque Rodríguez y Cía ${ }^{27}$, de Ramos Rejano ${ }^{28}$, y de Casa González ${ }^{29}$, extendiéndose su utilización hasta bien entrados los años 50. Su distribución por la ciudad cubana

${ }^{25}$ ZARDOYA LOUREDA, María Victoria: Ornamento por encargo..., op. cit., pp. 44-52.

${ }^{26}$ LÓPEZ GUZMÁN, Rafael y GARCÍA ACOSTA, Celia: "Oriente en La Habana. Reflexiones sobre el Neoárabe Hispanoamericano”, en FERNÁNDEZ VALLE, María de los Ángeles, OLLERO LOBATO, Francisco y REY ASHFIELD, Willian (Editores): Arte y Patrimonio en España y América. Montevideo, 2014, pp. 209-232.

${ }^{27}$ El origen de esta fábrica está en 1889 constituyéndose como sociedad tripartita entre los hermanos José y Enrique Mensaque y Vera y Fernando Soto y González, con el nombre comercial de "José Mensaque, Hermanos y Compañía". http://www.retabloceramico. net/bio2_mensaquehermanoycia.htm. (Consultado el 03-12- 2014).

${ }^{28}$ Está fabrica radicada en el barrio de Triana de Sevilla fue fundada en 1895 por Manuel Ramos Rejano. A la muerte del fundador continuaría su labor con el nombre de "Viuda e Hijos de Ramos Rejano" y, posteriormente, como "Hijos de Ramos Rejano" hasta 1965. http://www.retabloceramico.net/bio2_ramosrejanomanuel.htm. (Consultado el 03-12-2014).

${ }^{29}$ Casa González, Casa González Álvarez-Ossorio o también González Hermanos es la razón social de una empresa constituida en torno a 1902. Aunque esta empresa familiar dedicó su actividad principalmente a la venta de materiales de construcción y saneamiento, tuvo 
abarca multitud de edificaciones ${ }^{30}$ donde de forma esporádica aparece un zócalo, un tema figurativo ${ }^{31}$, el enmarque de vano o una fachada completa como decoración ajena a la estética conjunta de la edificación, aunque no siempre recurriendo a formulas neoárabes sino propuestas más genéricas donde el neorrenacimiento tiene mucho que decir ${ }^{32}$. En este sentido y en relación con las fundaciones de carácter regional español destacan los grupos de azulejos del Hotel Inglaterra, de la Casa de Andalucía en La Habana, situada desde 1919 en el Paseo del Prado n ${ }^{\circ}$ 109 y recientemente reubicada en el número 356 del mismo Paseo con la instalación ornamentista de algunas de estas piezas cerámicas. Citar, también, la zapatería ubicada en la calle O'Reilly o el edificio de oficinas de José Álvarez.

Un caso excepcional presenta el Hotel Inglaterra que abre su fachada al Parque Central junto al Gran Teatro de La Habana. Su construcción nos lleva hasta $1850^{33}$, aunque entre 1891 y $1915^{34}$ sería totalmente reconstruido otorgándole, entonces, la imagen ecléctica de marcado clasicismo. Su relación con el neoárabe aparece en el tratamiento del interior, más concretamente en el lobby y en el denominado Patio Sevillano, espacio de restaurante. Dicho patio, separado de la recepción con rejerías neorrenacentistas, es techado y la cubierta se apoya en pilastras de capiteles formados por mocárabes. Predominan los arcos de medio punto que descansan en ménsulas también de mocárabes o en gruesas columnas clasicistas. Estos arcos sirven de soporte, en algunos casos, a vitrales que separan el patio de otros espacios contiguos. La superficie de las paredes está cubierta con grandes paneles de cerámica vidriada con formas vegetales y geométricas, las cuales se utilizan también como zócalos. Esta azulejería procede de la fábrica Pickman de la Cartuja de Sevilla. Es importante destacar la presencia de la epigrafía árabe, que,

una interesante faceta en lo referente a la cerámica artística decorativa y devocional. http:// www.retabloceramico.net/bio2_gonzalezcasa.htm. (Consultado el 03-12- 2014).

${ }^{30}$ PÉREZ GUILLÉN, Inocencio V: Las azulejerías de La Habana. Cerámica arquitectónica española en América. Valencia, 2004, pp. 257-267.

${ }^{31}$ Entre ellos destacamos por su relación con la fábrica sevillana de Mensaque y ejecutados en técnica de cuerda seca la "Adoración de los Reyes" situada en el compás de entrada a la iglesia de los Betlemitas, fechado en 1925, y los dos cuadros situados en el interior de la Casa de Andalucía que representan "La pava del contrabandista" y "De la Feria", claramente inspirada, esta última, a nivel de composición en el lienzo "En la feria de Sevilla" de Manuel Cabral Aguado Bejarano (1827-1891).

${ }^{32}$ Quizás el programa más interesante con temáticas neorrenacentistas sea el arrimadero de la iglesia de Nuestra Señora del Carmen realizado por la Casa González de Sevilla entre 1931 y 1939. Cfr. PÉREZ GUILLÉN, Inocencio V: Las azulejerías de La Habana..., op. cit., pp. 341-355.

${ }^{33}$ CUEVAS TORAYA, Juan: 500 años de construcciones en Cuba. La Habana, Chavin, 2001, pp. 90-91.

${ }^{34}$ MARTÍN ZEQUEIRA, María Elena y RODRÍGUEZ FERNÁNDEZ, Eduardo Luis: La Habana Colonial: guía de arquitectura (1519-1898). Sevilla, 1993, p. 79. 
aunque a poca escala, aparece en lugares puntuales: sobre los azulejos de la base de las pilastras o como detalles en los mocárabes de las ménsulas. La definición de este espacio hotelero mediante la presencia masiva de cerámica vidriada nos permite valorar la importancia de azulejos procedentes de Sevilla, así como de otros centros productores españoles ${ }^{35}$.

De verdadero interés eran los arrimaderos de la fachada del Centro Andaluz de La Habana, también situado en el Paseo del Prado, recientemente reubicado habiendo perdido parte de este patrimonio, presentando azulejos de cuenca o arista que incluían en su parte central referencias simbólicas a Sevilla con la presencia de Fernando III, San Isidoro y San Leandro realizados en cuerda seca. Esta cerámica neomudéjar fue comercializada por las industrias de Ramos Rejano y de Mensaque a fines del siglo $\mathrm{XIX}^{36}$.

La influencia de la arquitectura neoárabe llega a Cuba por diferentes vías. Entre ellas tenemos que valorar la apertura de la isla al mundo a principios del siglo XX, permitiendo que turistas cubanos visitaran la Alhambra de Granada o, por el contrario, que emigraran hacia Cuba un alto número de españoles en busca de la "tierra prometida" evitando, entre otras realidades, la guerra de Marruecos. Por otro lado, con el afán de buscar una imagen propia y tratar de olvidar el pasado, los cubanos volcaron todas las miradas hacia Europa tomando referencia de las publicaciones extranjeras o nacionales que informaban del estado de la arquitectura en el mundo, así como de las modernidades exhibidas en las frecuentes Exposiciones Internacionales, espacios donde el neoárabe no era una excepción.

Este neoárabe habanero se extiende desde el Paseo del Prado con edificaciones privadas o de servicios, fundamentalmente hoteles. Sus referencias estructurales pasan por los edificios fundamentales del arte andalusí (Alhambra de Granada, Mezquita de Córdoba, Giralda de Sevilla), pero adaptados al cromatismo y a la vocación urbana de las calles habaneras. No faltan otras referencias culturales islámicas como el ámbito de la Turquía otomana de forma puntual en remates de edificios o en sistemas de arcos. En los interiores la relación con los palacios nazaríes es muy directa, teniendo presencia, en estos casos, la difusión de la obra de Owen Jones. Elementos epigráficos, geométricos o atauriques están tomados directamente de la obra del viajero y diseñador inglés.

El repertorio de construcciones neoárabes, que irían desde el Palacio de la Ursulinas hasta el hotel Sevilla pasando por el castillo de los Jardines de la Tropical o la vivienda situada en el Paseo del Prado número 314, combinan realizaciones que marcan el viario público con soluciones de interior de enorme originalidad.

${ }^{35}$ Ya hemos señalado la presencia de cerámica en el vestíbulo del hotel Sevilla, igualmente sucede en el del hotel Nacional, aunque en este caso habiendo perdido casi la totalidad de los elementos originales. Ibídem, p.129.

${ }^{36}$ Cfr. PÉREZ GUILLÉN, Inocencio V: Las azulejerías de La Habana..., op.cit., pp. 257-258. 
Consideramos que, como conjunto, la capital cubana reúne el catálogo más copioso y original de toda Iberoamérica en una sola ciudad.

Este oriente habanero es perceptible en el grupo de arquitecturas referidas, pero también se puede rastrear en otros ámbitos de la vida de la ciudad donde nominaciones como el Teatro Alhambra ${ }^{37}$ o imágenes comerciales como los puros de Santa Damiana o La Honradez ${ }^{38}$ son recuerdos de una mezcolanza cultural, generalmente poco comprendida, pero aceptada en su misterio y originalidad.

Por tanto, y a modo de conclusión, considero que las acciones arquitectónicas derivadas de la presencia de asociaciones españolas de carácter regional, unidas a personalidades también procedentes de España, conjuntamente con formas arquitectónicas orientalistas pero inspiradas en los grandes edificios de Al-Andalus, permiten una valoración positiva y significativa de lo hispano, en el sentido mas amplio, dentro de la arquitectura de La Habana, proyectos que arrancan en la segunda mitad del XIX y que se concluyen o visualizan en las primeras décadas del siglo XX.

Fecha de recepción: 30 de septiembre de 2014

Fecha de aceptación: 28 de noviembre de 2014

${ }^{37} \mathrm{La}$ historia y ambiente de este teatro se pueden visualizar en la película "La Bella de la Alhambra" (1990) una producción hispano-cubana dirigida por Enrique Pineda Barnet.

${ }^{38}$ Se trata de la Real e Imperial Fábrica de Luis Susini e Hijos, los cuales eran propietarios de La Honradez. Lo interesante de este diseño es que aparece un pabellón orientalista de la exposición de París de 1867. Diseños que llegaban mediante las revistas de moda y también de arquitectura. 


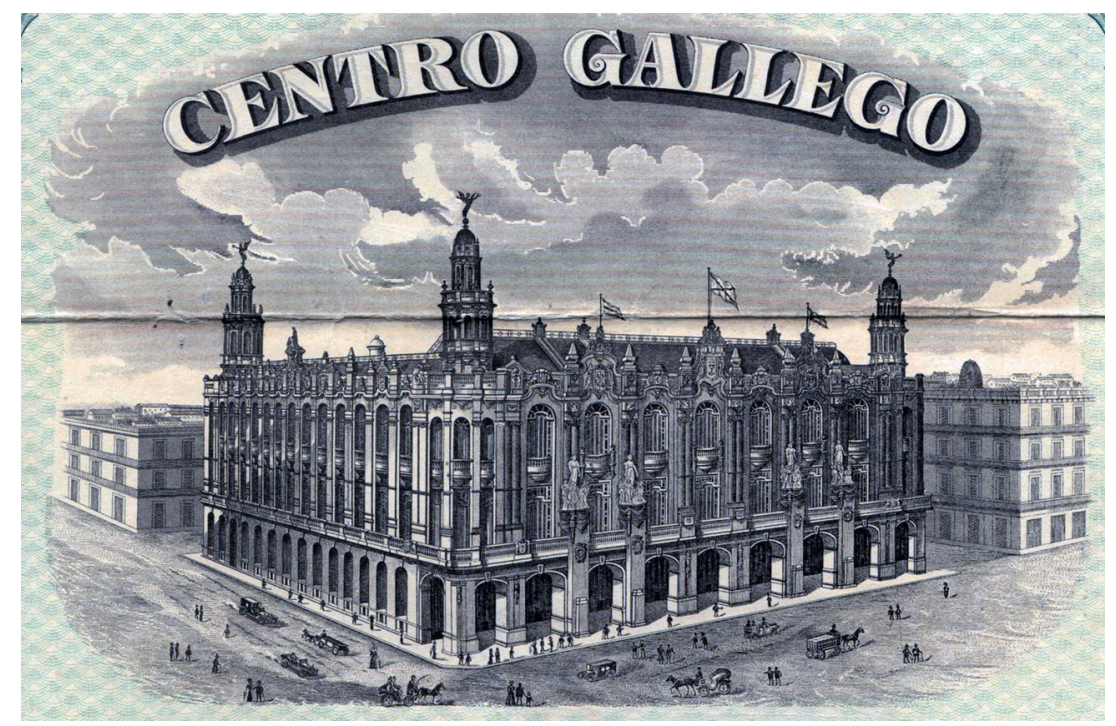

Figura 1. Centro Gallego. Litografía.

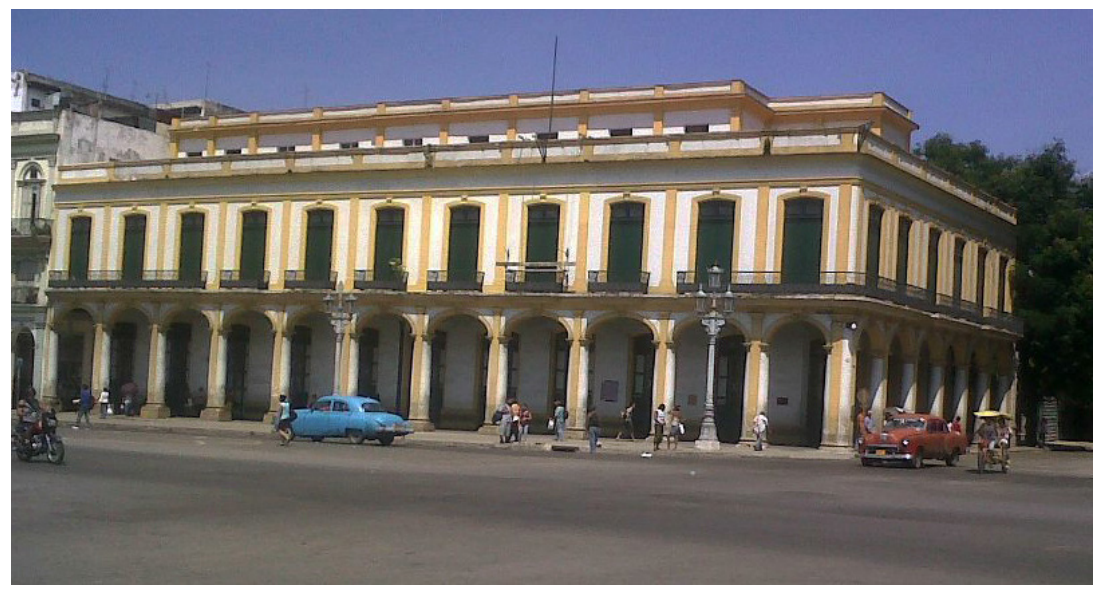

Figura 2. Centro de enseñanza Concepción Arenal. 


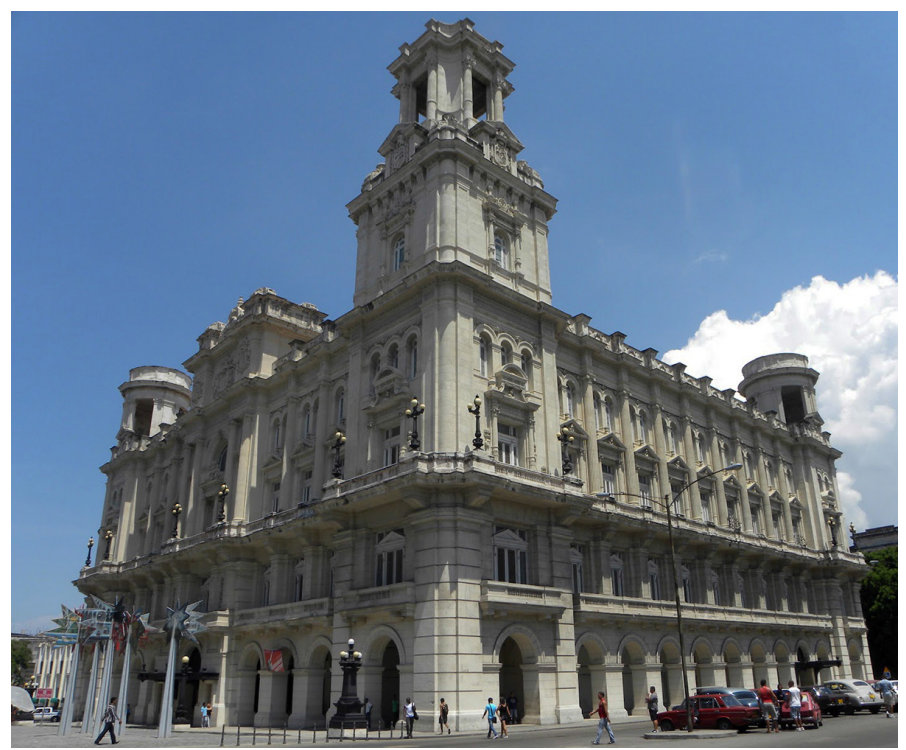

Figura 3. Centro Asturiano.

Figura 4. Casino Español.

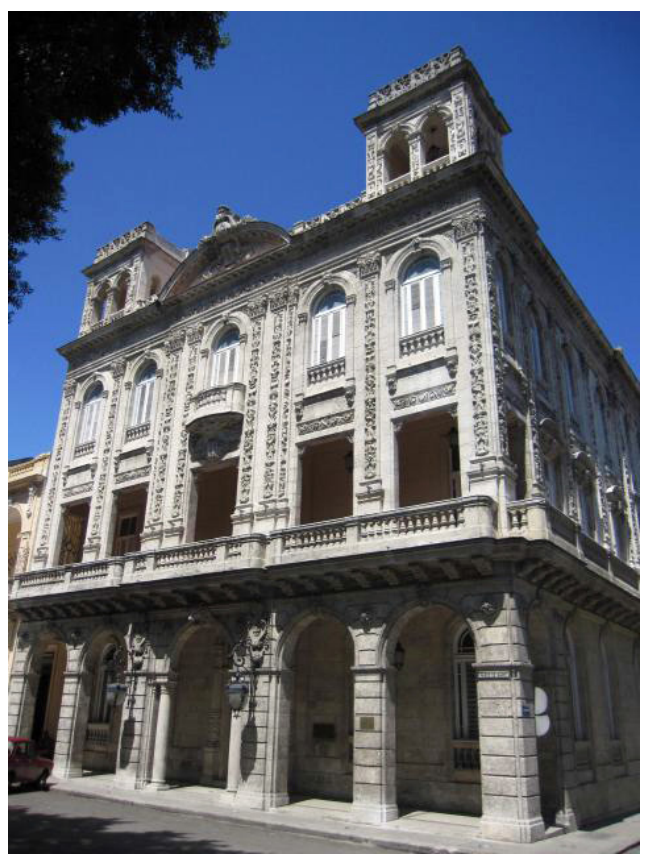




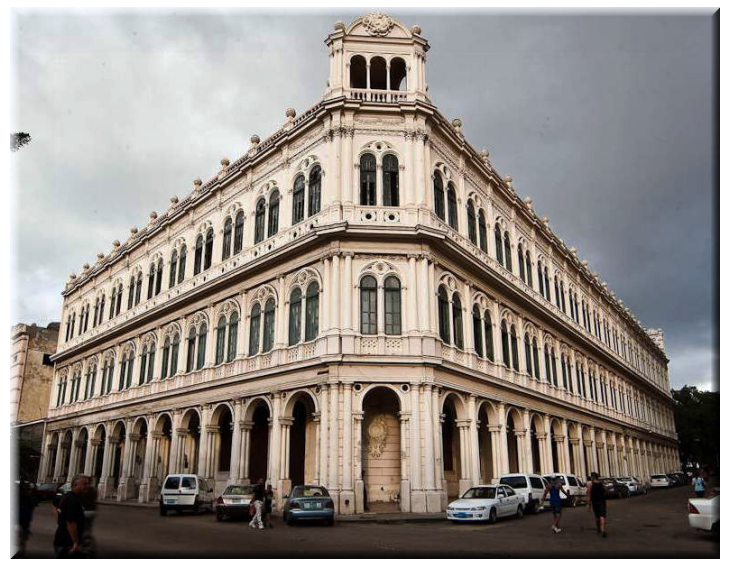

Figura 5. Sociedad de dependientes del comercio.

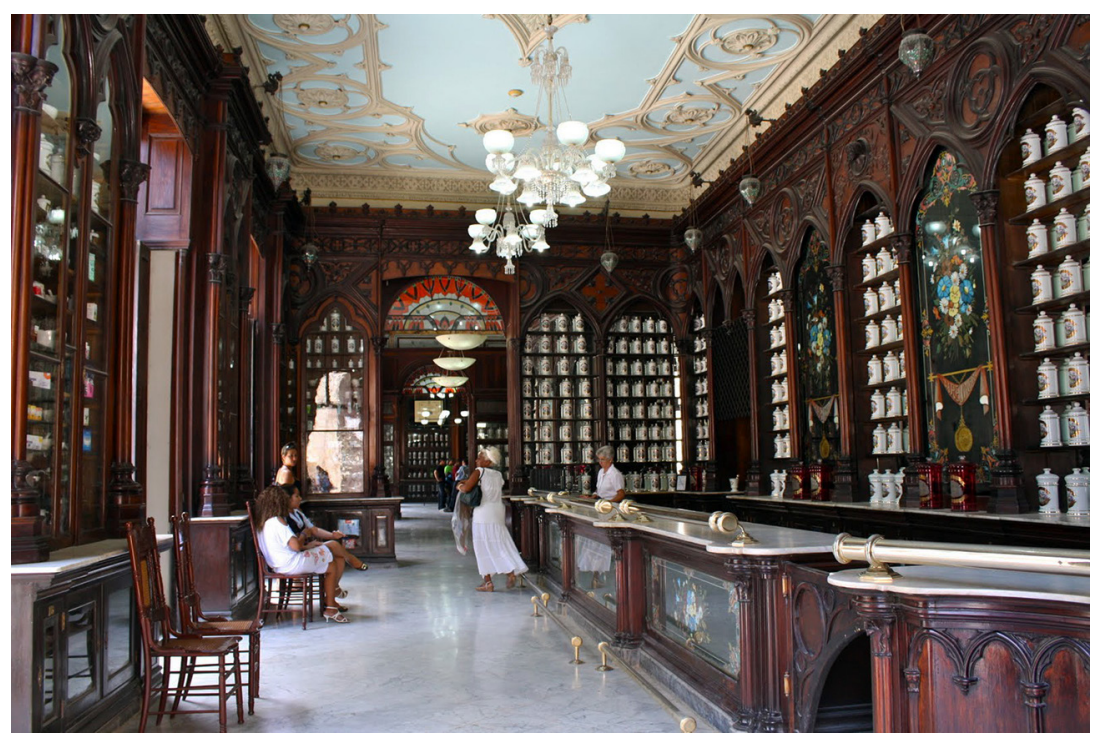

Figura 6. Farmacia La Reunión. 


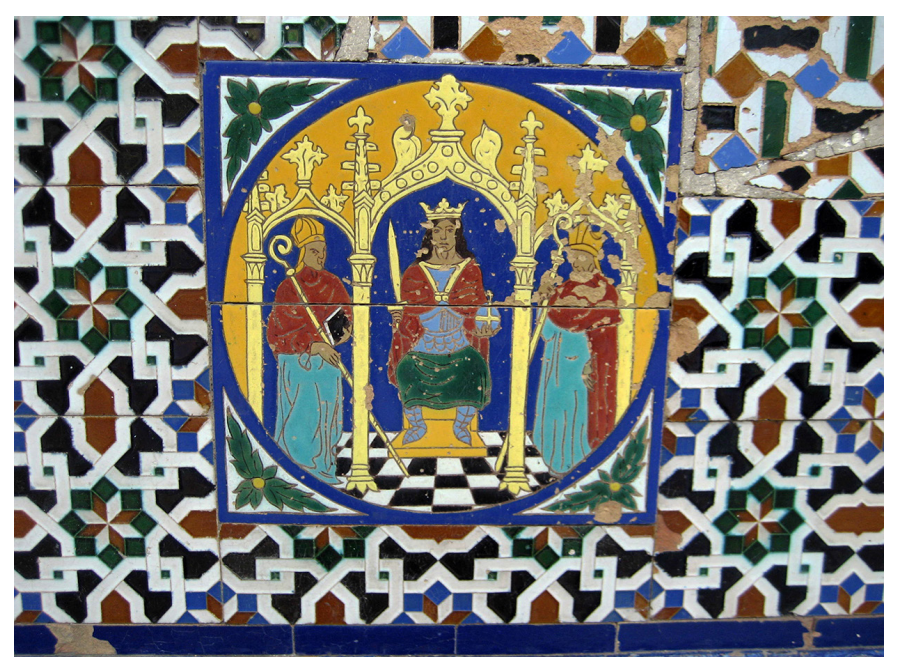

Figura 7. Escudo de Sevilla. Zócalo antigua Casa de Andalucía.

Figura 8. Hotel Sevilla.

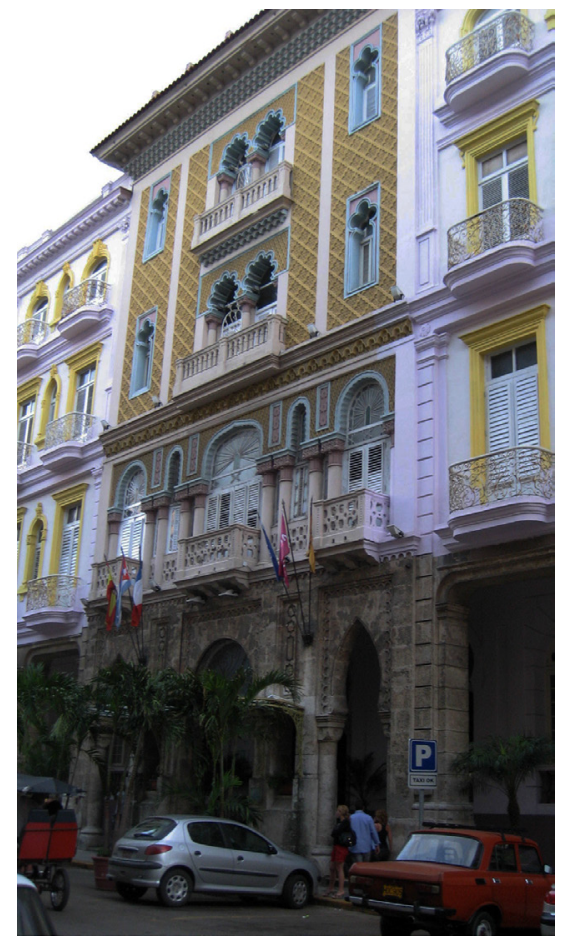




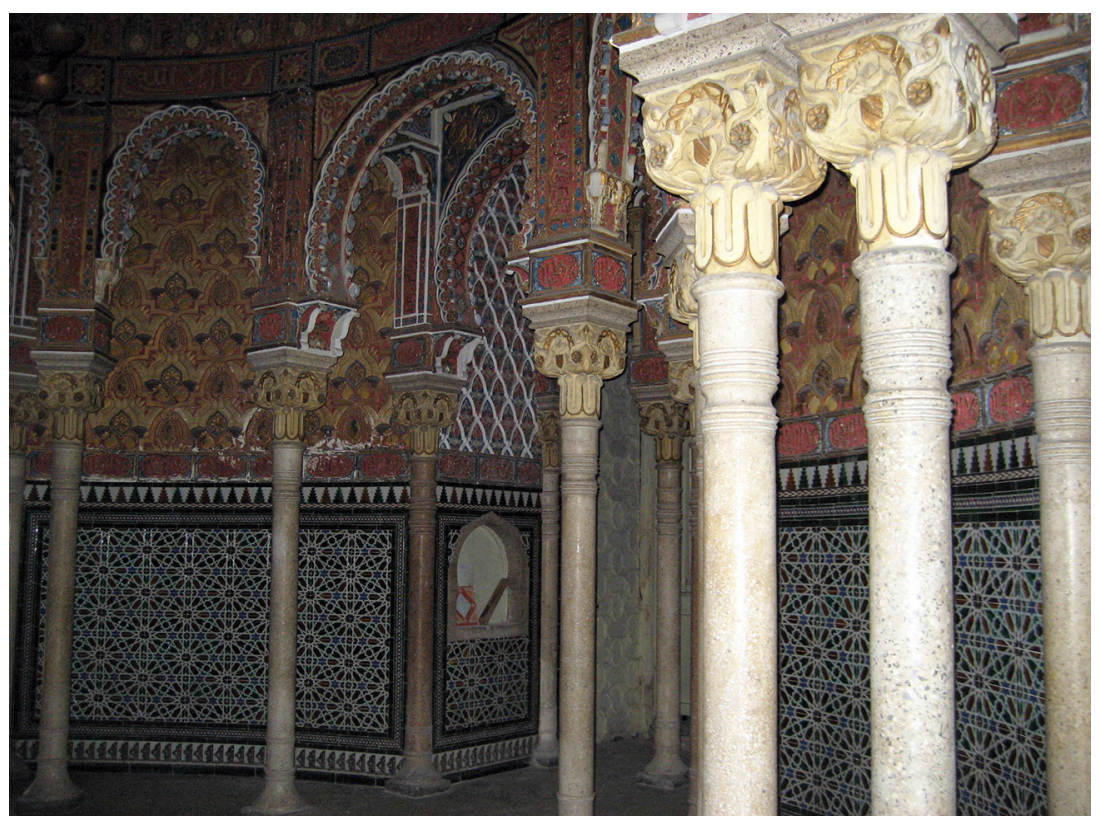

Figura 9. Castillo neoárabe en los Jardines de la Tropical. Interior.

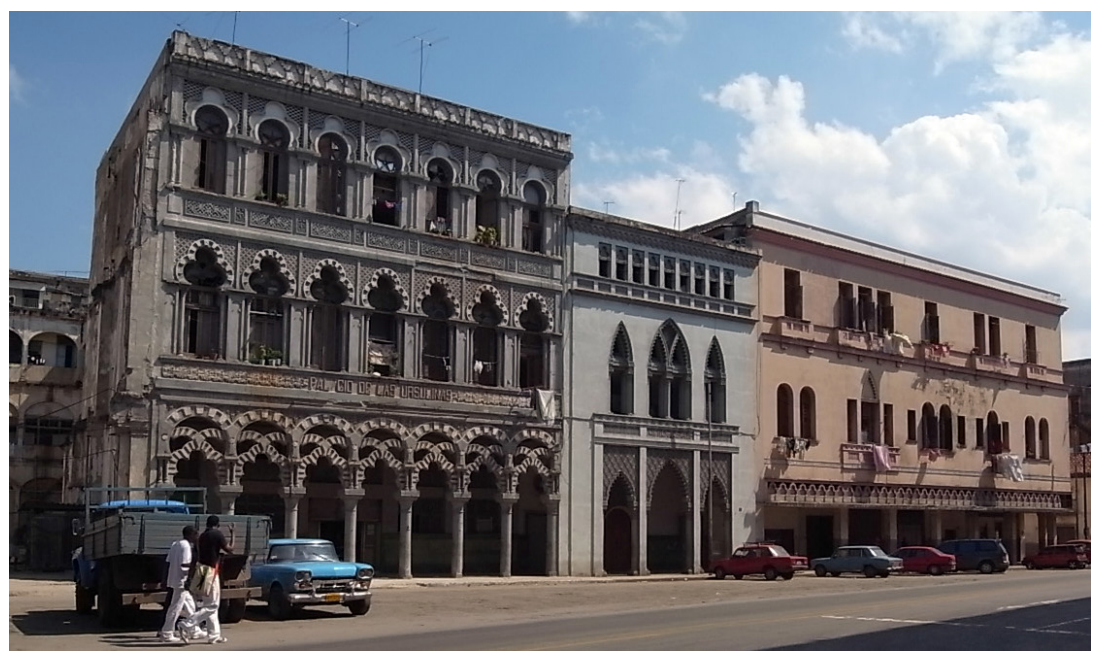

Figura 10. Castillo neoárabe en los Jardines de la Tropical. Interior. 